\title{
SOBRE PASSAGENS SELECIONADAS DO ULYSSES, SUAS TRADUÇÕES E TRADUTORES ${ }^{1}$
}

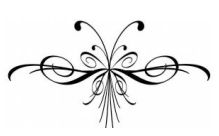

Gustavo AlthofF \& Jolanta WAWRZYCKA

s sete passagens do Ulysses apresentadas neste dossiê -
"Ulysses Traduzido ao Português" - representam um amplo
Lespectro da experimentação estilística de Joyce. Elas são suficientemente desafiadoras para um leitor nativo, mas apresentam um conjunto bem diferente de desafios ao tradutor. A língua de Joyce está crivada de nuances e sutilezas; algumas delas são imperceptíveis aos leitores, mas desconcertam os tradutores. A abertura de "Telemachus" (Telêmaco)2, "Stately, plumb Buck Mulligan came from the stairhead (...)”, pode não parecer impor dificuldade alguma, até o momento em que o tradutor tenha de decidir por seus leitores acerca da natureza (e referência) da palavra de abertura, "Stately." A passagem também introduz algumas alusões religiosas ou clássicas que ajudam a dar o tom de "Proteus" (Proteu) - capítulo cuja abertura os tradutores podem vir a achar bastante exigente, linguística e estruturalmente, à medida que navegam pelas inelutáveis preocupações filosóficas hiperestilísticas de Stephen, enquanto esse caminha, famosamente, por Sandymount Strand.

De um modo geral, os tradutores podem vir a achar o linguajar e os pensamentos de Stephen mais difíceis de traduzir do que os de Leopold Bloom. Mas uma breve passagem "sanduíche" de "Lestrygonians" (Os lestrígones) está crivada de trocadilhos, sutilezas paronomásticas, referências

\footnotetext{
${ }^{1}$ Neste texto Wawrzycka se ocupou dos comentários a respeito das passagens de seis capítulos do Ulysses que figuram neste dossiê, ao passo que Althoff dedicou-se a coletar e editar as informações sobre as traduções e os tradutores do Ulysses ao português. Wawrzycka escreveu sua contribuição em inglês, a qual foi posteriormente traduzida por Althoff ao português do Brasil.

${ }^{2}$ Os nomes em português dos capítulos de Ulisses aqui mencionados foram tirados da tradução de Bernardina da Silveira Pinheiro.
} 
interculturais, ou de um humor negro literário/canibalista, em número suficiente para dar dores de cabeça ao tradutor, particularmente porque muitos desses elementos reaparecem ao longo do Ulysses em variados contextos (o que sugere a necessidade de um alto grau de uniformidade lexical).

A abertura do episódio "Sirens" (As sereias) pode parecer, num primeiro momento, uma acumulação randômica de construtos onomatopéicos - será um desafio aos tradutores preservar o trecho "steelyringing Imperthnthn thnthnthn" na ocorrência de abertura e à medida que recorre no contexto do episódio. Muitas estruturas desse tipo ("My eppripfftaph. Be pfrwritt. Done") exigem que elas sejam recriadas de uma maneira que se ajustem ao restante do capítulo e do Ulysses.

No que tange ao capítulo "Oxen of the Sun" (O Gado do Sol), notoriamente difícil, faz-se apropriado citar o patrono das áreas dos estudos joyceanos e das traduções de Joyce, Fritz Senn: “As rápidas transformações de estilo que caracterizam o capítulo Oxen of the Sun poderiam também ser vistas como uma série de traduções: não do tipo horizontal, de uma língua para outra, mas traduções verticais, que perpassam estágios progressivos da linguagem literária e, claro, chegam ao uso singular dos escritores individualistas. Essa é uma das razões de os tradutores considerarem esse capítulo particularmente frustrante." ${ }_{3}$ Tais estágios progressivos da linguagem literária variam grandemente de uma nação para outra e acredito que tal aspecto é particularmente desafiador aos tradutores: como proceder quando uma língua (e.g., o polonês) não possuir um estágio paralelo ao do inglês antigo (Old English)? Palavra por palavra, supõe-se, e com a menor quantidade de frustração possível.

A última seleção apresentada vem de "Ithaca" (Ítaca) e oferece uma descrição espetacularmente rica das características da água, tão admiradas por Leopold Bloom. A exuberância dessa passagem é capaz de estender qualquer linguagem ao máximo de sua capacidade, à medida que os tradutores avancem em sua labuta para verter a virtuosidade de Joyce.

Os leitores são convidados a examinar, a meditar, a admirar, a criticar e, se necessário, a exprimir suas insatisfações à medida que forem lendo as palavras de Joyce em português. Um tal "joyceamento" via tradução oferece recompensas de um tipo diferente - há grandes alegrias que advém de se ter "comprendido com surpresa" $(U \text { 17.700 })^{4}$.

Esse "contexto de descoberta" do Ulysses via as passagens selecionadas em tradução é aqui ofertado de maneira sinótica, isto é, através da ex-

\footnotetext{
${ }^{3}$ SENN, Fritz. Tradução como Abordagem [tradução de Luana Ferreira de Freitas e Alessandra Ramos de Oliveira Harden]. Scientia Traductionis, Florianópolis, n. 8, dez 2010.

${ }^{4}$ Entre os estudiosos da area esta é a referência padrão para o Ulysses de Joyce e refere-se a "Gabler edition."
} 
posição de original e traduções lado-a-lado, num único documento, em ordem de exposição que obedece a senioridade dos textos - Joyce vem à frente, seguido das traduções de Houaiss, Palma-Ferreira, Pinheiro e, por fim, Galindo. Além disso, em proveito da versatilidade do meio eletrônico, essas passagens também são ofertadas em tabelas individuais contendo, cada arquivo, original e uma das traduções. ${ }^{5}$

Este dossiê conta ainda com dois artigos que analisam alguns aspectos das duas primeiras traduções brasileiras do Ulysses e um terceiro artigo que analisa as considerações teóricas de Galindo em sua tese de doutorado ${ }^{6}$, obra na qual "buscou verificar em que medida o esquema bakhtiniano de análise da narrativa literária se adéqua ao estudo dos mecanismos de representação do discurso e ao convívio entre personagens e narrador no romance de Joyce" ". Os artigos "O Ulysses de Joyce reescrito por Houaiss: problemas de tradução e as soluções encontradas", de Áureo Lustosa Guérios Neto, e "O Ulysses de James Joyce e a tradução de Bernardina da Silveira Pinheiro", de Jonathas Rodrigo Bitencourt Duarte, se ocupam da primeira tarefa, ao passo que "Bakhtin, Joyce e Galindo: as diferentes vozes na teoria, no original e na tradução", de Fabrízia Carvalho Ribeiro, se ocupa da segunda. Todos os três autores são jovens pesquisadores da obra de Joyce oriundos da Universidade Federal do Paraná.

As traduções do Ulysses ao português tem uma história e um contexto - a bem dizer, múltiplas hisórias e múltiplos contextos - e faz-se necessário que provamos neste texto uma oferta inicial de informação ao leitor, qual seja, uma contextualização mínima dessas traduções e de seus tradutores. Comecemos pelo começo.

Antônio Houaiss (1915-1999), filólogo, escritor, crítico literário, enciclopedista, diplomata, ex-ministro da Cultura e membro da Academia Brasileira de Letras, foi o primeiro tradutor do Ulysses ao português 8 . Não é nenhuma espécie de heresia, nem histórica, nem crítica ou acadêmica, afirmar que a recepção da tradução de Houaiss carrega consigo o estigma, ou fama, de uma suposta dificuldade de leitura maior do que a do próprio original do

\footnotetext{
${ }^{5}$ Informamos que caso algum pesquisador necessite dos arquivos das passagens traduzidas noutros formatos, Scientia Traductionis pode fornecê-las em ."docx" ou ."doc." Escreva ao e-mail da revista: Revista Scientia Traductionis" <scientiatraductionis@gmail.com>.

${ }^{6}$ GALINDO, Caetano Waldrigues. Abre aspas: a representação da palavra do outro no Ulysses de James Joyce e seu possivel convívio com a palavra de Bakhtin. Tese de doutoramento. Universidade de São Paulo, orientador: José Luiz Fiorin, 2006.

${ }^{7}$ RIBEIRO, Fabrízia Carvalho. Bakhtin, Joyce e Galindo: as diferentes vozes na teoria, no original e na tradução. Scientia Traductionis, Florianópolis, n.8, dez 2010.

${ }^{8}$ JOYCE, James. Ulisses. Trad. de Antônio Houaiss. Rio de Janeiro: Civilização Brasileira, 1966.
} 
autor irlandês, apresentando diversos resultados de natureza excêntrica e, para muitos, intransponível9.

Em entrevista ao Programa Roda Viva de 10 de Dezembro de $1990^{10}$, Houaiss teve a oportunidade de se defender dessas "acusações" e falou das revisões que fez para as segunda e terceira edições de sua tradução; isso disse:

No meu caso concreto, (...) a proposta para mim foi esta: "como é que irei fazer um paralelismo entre a língua portuguesa e a original, tendo em vista as acrobacias que Joyce fez para com o inglês?" E não tive dúvida. Permiti várias propostas: ser tão conciso quanto Joyce, o que ele dizia numa palavra tentar dizer numa palavra. $\mathrm{O}$ que já era um repto não pequeno, dado o caráter um pouco mais sintético do que o inglês para com o português. E, nessa base, o que era uma palavra portmanteau, que era uma palavra forjada [pela junção de outras duas], eu buscava a correspondente em português, fazendo uma análise morfo-semântica do texto de origem e buscando conseguir o melhor resultado em português. Graças a isso, pude aproximar-me de uma tradução que seria satisfatória para mim. Tive a ventura de ter uma série de críticas feitas por dois grandes críticos: um, o Augusto de Campos, irmão de Haroldo de Campos, que numa série de artigos analíticos no Estado de S. Paulo, me sugeriu indiretamente... eu é que assumi o compromisso de, na segunda reimpressão, colocar segunda edição e aproveitar muitas das sugestões por ele feitas. Aí parei com o Ulisses, achando que havia realizado o que era o meu objetivo. O êxito foi grande, mas houve críticas do tipo seguinte - não vou citar a pessoa -: "É mais difícil ler em português do que ler o original". Disse com toda a sinceridade: "Acho que sim, porque em geral o leitor de inglês tem uma boa formação de inglês e o leitor em português tem uma má formação portuguesa". E, graças a essa... Infelizmente, não graças, desgraças a essa circunstância, há um grande número de aspirantes à leitura que compraram o exemplar e até hoje estão esperando a oportunidade de poder lê-lo. No momento, eu, com o Waltensir Dutra, estamos fazendo uma revisão, porque os textos traduzidos na base das versões anteriores foram interditados pela Fundação Joyce. Eles pedem que se leve em conta o texto crítico, recentemente estabelecido por uma equipe de estudantes, de estudiosos do texto original da Alemanha ${ }^{11}$ que apuraram em torno de cinco mil infidelidades para com o texto manuscrito, das quais pelo menos umas quinhentas têm repercussão na tradução.

\footnotetext{
${ }^{9}$ Cf. QUIRINO, Maria Teresa. Uma odisséia tradutória do Ulysses: análise das traduções da obra de James Joyce, Dissertação de mestrado. Universidade de São Paulo, orientador: John Milton, 2007.

${ }^{10}$ HOUAISS, Antônio. Entrevista ao Programa Roda Viva da TV Cultura. São Paulo, 9 dez. 1990. Arquivo do Roda. Disponível em:

$<$ http://www.tvcultura.com.br/rodaviva/programa/pgm0232>. Acesso em: 15 novembro 2010.

${ }^{11}$ Trata-se da "Gabler Edition”, de 1984.
} 
Num momento posterior lhe é perguntada sua opinião sobre a segunda tradução do Ulysses para a língua portuguesa, a de João Palma- Ferreira [(1931-1989) escritor, ensaísta, crítico literário e tradutor português], publicada no ano do falecimento desse. Ao comentar sobre ela, Houaiss revela um procedimento tradutório seu, também algo que é uma dificuldade de tradução do Ulysses e, en passant, "alfineta" a tradução que sucedeu à sua:

Eu evidentemente não me pronunciei, porque seria de suprema deselegância dar uma opinião a respeito dessa tradução. Essa tradução, antes de ser feita, houve uma proposta segundo a qual a minha tradução seria adaptada. E realmente os portugueses devem estar um pouco constrangidos com a minha tradução, porque o capítulo XVIII ou XVII é um capítulo em que há uma linguagem de gíria inglesa de 1904. Não sei se é gíria inglesa ou gíria americana de 1904. Como é que eu poderia fazer gíria? A não ser a gíria carioca, era a única que me era acessível, senão teria que fazer uma sondagem do impossível. Que gíria iria eleger? Carioca que sou, nascido lá, estudando aquela língua de sempre, fiz em gíria carioca! E fiz mais: fiz em gíria carioca de 1904. [risos] O requinte foi esse. É claro que, para o português, aquilo ficou um enigma. Aquele capítulo é enigmático. Então, eles propunham fazer uma modificação desse capitulo e, en passant [de passagem], umas outras quantas. Foi nesse en passant e umas outras quantas que não concordei. Então, o Palma, que era editor - não se esqueça disso -, um homem de certo mérito, fez a tradução portuguesa. Mas, muito entre nós, evidentemente ele pôde fazê-la porque já havia uma anterior. [risos]

Com os comentários de Houaiss frescos na memória, miremos a tradução de João Palma-Ferreira. Antes, uma sua biografia abreviada. Ficcionista, crítico, tradutor e historiador literário, João Palma-Ferreira foi diretor literário da Editora "Livros do Brasil", professor universitário e presidente do Instituto Português do Património Cultural, além de ter exercido outras ocupações. Deixou vasta obra, portanto, como ficcionista, memorialista, crítico, tradutor e gestor cultural.

A história de sua tradução do Ulysses está, em grande medida, relacionada com a de Houaiss, em contexto pontual e já minimamente explicado na fala do filólogo brasileiro. Vivina Almeida Carreira de Campos Figueiredo nos conta ${ }^{12}$ que ao longo de quase vinte anos a tradução de Houaiss foi discretamente vendida em Portugal e que "somente em 1983, a editora Difel, do mesmo grupo editorial da Civilização Brasileira, procedeu à publicação da obra em Portugal, apenas com uma adaptação ortográfica. Menos de um

${ }^{12}$ FIGUEIREDO, Vivina Almeida Carreira de Campos. Joyce em Português europeu. As funções dos paratextos em Exiles, Finnegans Wake, Giacomo Joyce, A Cat and the Devil e Querida Nora! O Língua, Lisboa, n.6, abril 2005. Disponível em: $<$ http://cvc.institutocamoes.pt/olingua/06/lingua02.htm>. Acesso em: 15 novembro 2010.

Scientia Traductionis, n.8, 2010 
ano depois, em Julho de 1984, contava três edições, tendo continuado a reeditar-se, com inúmeras reimpressões. Da obra consta uma nota do editor que diz o seguinte:

Nesta edição do Ulisses de Joyce utilizou-se a tradução brasileira por ser considerada internacionalmente a mais perfeita e aquela que mais fielmente se aproxima do texto original do grande romancista irlandês. Na presente tradução apenas se procedeu à actualização ortográfica.

Figueiredo observa também aquilo que já é bem sabido por quem já teve a tradução de Houaiss, seja aqui, seja acolá, em mãos: "a obra não contém nenhum prefácio, introdução ou nota explicativa como, aliás, era a vontade de Joyce, que o recomendara para que a obra fosse lida por si só." Continua e diz que apesar do sucesso editorial, a publicação da tradução de Houaiss:

suscitou algumas reacções adversas, tendo conduzido a editora Livros do Brasil a retomar o antigo projecto da tradução de Ulysses. Este era um projecto antigo desta editora, tendo sido entregue a Mário Henrique Leiria ${ }^{13}$ e posteriormente a Jorge de Sena ${ }^{14}$ que, por razões diversas, nunca chegou a ser concretizado.

Isso assim se deu, explica, por um lado em função da dimensão da obra e de sua dificuldade intrínseca, e, por outro porque as circunstâncias políticas de Portugal nos anos 60 e 70 "não convidavam nenhuma editora a correr o risco de fazer traduzir e pôr a circular uma obra considerada ofensiva da moral pública e dos bons costumes." Assim, a tradução de Palma-Ferreira, veio à tona somente em 1989.

A obra contava com uma breve "Nota do Editor", de António Luís de Souza-Pinto, "congratulando-se por ter sido o primeiro editor português de Joyce e por, após várias tentativas por outros tradutores, finalmente trazer a lume o Ulysses em «língua veramente portuguesa.» (p. 7).”

Por fim, reproduz-se aqui excerto do prefácio de Palma-Ferreira à sua tradução da peça "Exilados", também de Joyce, lançada em Portugal em 1987, pela mesma Livros do Brasil, em que numa página, em post scriptum, revela um tantinho do seu pensamento acerca do fazer tradutório:

Executar uma tradução é sempre, ou quase, um acto de puro atrevimento; ou uma traição; ou, mais raramente, uma divagação vasta e erudita, metódica e grave pela obra de um autor. Mas pode dar-se (e já tem aconteci-

\footnotetext{
${ }^{13} \mathrm{http}: / /$ acpc.bnportugal.pt/espolios_autores/e22_leiria_mario_henrique.html

${ }^{14} \mathrm{http}: / / \mathrm{cvc}$.instituto-camoes.pt/figuras/jdesena.html
} 
do...) que o convívio com um texto de autor estrangeiro, ou porque nos comove, ou porque o consideramos um "momento" imprescindível, ou porque, de muito o lermos já nos soa a português, acaba por operar, quase sem darmos pelo fenómeno, a epifania de uma transliteração súbita. Essas são as únicas traduções felizes, as raras, modestas obras de arte em que o transeunte literário não repara, tão ávido anda de pedantismos e de fazer seus os carmina aliena.

Da terceira tradução ao português, e segunda ao português do Brasil, encarregou-se Bernardina da Silveira Pinheiro (1922-). Pinheiro nasceu no Rio de Janeiro em 1922, diplomou-se em filosofia na antiga Universidade do Brasil, em 1949, cursou o Mestrado da Faculdade de Letras da Universidade Federal de Santa Catarina (UFSC) em 1974, e é professora emérita da Universidade Federal do Rio de Janeiro (UFRJ), onde defendeu tese de livredocência sobre a densidade semântica na poesia de Gerard Manley Hopkins (1974). Antecedente ao seu engajamento tradutório com o Ulysses, realizou pesquisas de pós-doutorado sobre a obra de Joyce e especificamente sobre o Ulisses, no University College, em Londres, e em Dublin, na Irlanda. É membra da International James Joyce Foundation e da Escola Letra Freudiana, tendo traduzido A Portrait of the Artist as a Young Man, também de Joyce ${ }^{15}$. Ainda hoje, no dia 16 de junho, organiza, no Rio de Janeiro, as comemorações do Bloomsday. ${ }^{16}$

Sua tradução do Ulysses foi lançada pela Editora Objetiva no dia 16 de junho de 2005 - dia do Bloomsday! A tarefa ocupou-a por sete anos e objetivou, alegadamente, conforme menções na imprensa, no site da própria editora $^{17}$ e mesmo na contracapa do livro "restituir o grande feito literário do século XX a quem de direito: o leitor. Com o mesmo registro coloquial do inglês usado por Joyce, mas sem abrir mão da riqueza linguística que o consagrou, a linguagem empregada nesta edição privilegia uma dimensão mais humana da obra-prima do autor, tornando-a acessível ao maior número possível de leitores." 18 Reproduz-se aqui um exemplo de recepção favorável da crítica:

Toda tradução impõe equilíbrio entre fidelidade e invenção. Bernardina inventa pouco, embora crie aqui e ali sintaxes e termos curiosos. Ela nivela as ousadias de Joyce para tornar a trama nítida. Houaiss rumou pelo avesso

\footnotetext{
15 JOYCE, James. Um retrato do artista quando jovem. [Por: Bernardina da Silveira Pinheiro]. Rio de Janeiro: Objetiva/Alfaguara, 2006. Contracapa.

${ }^{16}<$ http://www.dicionariodetradutores.ufsc.br/pt/BernardinaLeaMariadaSilveiraPinheiro.ht $\mathrm{m}>$

${ }^{17}<$ http://www.editoras.com/objetiva/673-1.htm>

18 JOYCE, James. Ulisses. [Por: Bernardina da Silveira Pinheiro]. Rio de Janeiro: Objetiva, 2005.
} 
e, não raro, operou por mera substituição. Seu monólogo íntimo se sobrepôs ao do original, criando um quase-romance alusivo ao Ulisses real, de 1922, por sua vez paródia da Odisséia de Homero e marco fundador da narrativa experimental. A ficção de Houaiss soa mais tortuosa - e chata - que a de Joyce. A nova versão revela o narrador boêmio e rico em truques. ${ }^{19}$

Se conseguiu ou não o feito alegado pela crítica no pós-lançamento de sua tradução é algo que cabe ao julgamento de cada leitor e crítico individual, e da pesquisa acadêmica for years to come.

O quarto e mais recente tradutor do Ulysses para o português chamase Caetano Waldrigues Galindo. Professor da Universidade Federal do Paraná (UFPR), formou-se e tornou-se mestre em Letras por essa instituição em 1998 e em 2000, e em 2006 graduo-se Doutor em Linguística pela Universidade de São Paulo. Tem trabalhado com James Joyce, teoria da tradução e representação do discurso no romance, e se considera, acima de tudo, um linguista. ${ }^{20}$ Sua tradução foi realizada num período de dois anos dentro de seu doutorado (2002-2006) $)^{21}$ e, segundo o seu site pessoal ${ }^{22}$, encontra-se em processo de revisão detalhada, com publicação confirmada e contratada, e expectativa de lançamento para o começo de 2012.

Algumas opiniões suas sobre o Ulysses em tradução foram colhidas em duas entrevistas realizadas por Sérgio Medeiros e Dirce Waltrick do Amarante, do site Centopéia ${ }^{23}$. Apesar das entrevistas serem interessantes em suas integralidades, reproduzimos aqui algumas passagens que julgamos de particular interesse para uma primeira aproximação com o tradutor e o seu pensamento em torno ao Ulysses e suas traduções.

Da primeira, arguido sobre o espanto que se possa ter com a notícia de mais uma tradução do Ulysses ao português, Galindo emite uma opinião borgeana sobre o tema; diz ele: "as traduções envelhecem mais rápido que os originais, e me parece incrivelmente saudável que os 'classicões' vivam sendo retraduzidos, como contribuição de cada geração à sua literatura e como exercício para cada uma delas."

Perguntado sobre em que momento de sua vida surgiu o desejo de traduzir o Ulisses, e sobre como cumpriu esse desejo, Galindo também faz uma crítica expressa à tradução de Houaiss; declarou:

\footnotetext{
${ }^{19}<\mathrm{http}$ //revistaepoca.globo.com/Epoca/0,„EPT976610-1661,00.html>

${ }^{20}$ Informações obtidas no Currículo Lattes de Galindo:

$<$ http://buscatextual.cnpq.br/buscatextual/visualizacv.jsp?id=K4767483U8>.

${ }^{21}$ Cf. RIBEIRO, Fabrízia Carvalho. Bakhtin, Joyce e Galindo: as diferentes vozes na teoria, no original e na tradução. Scientia Traductionis, Florianópolis, n.8, dez 2010.

${ }^{22} \mathrm{http} / / /$ sites.google.com/site/cwgalindo/

${ }^{23} \mathrm{http}: / / \mathrm{www} . c e n t o p e i a \cdot n e t /$
}

Scientia Traductionis, n.8, 2010 
De trás para frente. Só consegui cumprir o desejo porque dei um jeito de transformar o desejo em um projeto acadêmico consistente e porque trabalho em uma universidade pública, que ainda demonstra interesse em titular seu pessoal à custa de alguns anos de afastamento dos encargos didáticos. Não teria sido possível, em quatro anos, escrever o meu texto teórico para o doutoramento, e mais a tradução, sem essa possibilidade, que os meus colegas e o sistema federal me garantiram.

Mas o desejo surgiu aos poucos. Primeiro eu, na graduação, resolvi imitar um amigo meu e ler o "Ulysses." Mas me detive. Maldadinhas à parte, não consigo dedicar energia a ler um catatau daquele tamanho que comece com "Sobranceiro e fornido." Um bom livro, idealmente, sequer deve ter UMA dessas palavras, em qualquer momento. Que dirá as duas! E na primeira linha!!

Aí fui polir o meu inglês.

No fim dos anos 90 tentei de novo. E esse contato que começou ali me levou até 2000, quando tive de desistir (por motivos pessoais) de uma bolsa de doutorado na Alemanha. No interlúdio meio hedonista que se seguiu a essa decisão bem difícil, decidi que a romanística podia ficar sem mim agora que os alemães também ficariam. Quis criar um novo projeto de doutoramento que, um, me divertisse e me fizesse realmente crescer; dois, gerasse algo mais que uma tese; três, não me enchesse de tédio depois de dois, três anos... Aí, num acesso fáustico em uma caminhada pelo jardim botânico de Curitiba eu disse "vou traduzir o Ulysses", o que me dava a melhor das oportunidades para finalmente ler esse livro com o grau de lente de aumento que ele exige. Eu sou um mal primeiro leitor (apressado e leviano), mas sou bem melhor de segundas e terceiras, e esse projeto me obrigou a ir bem além de duas ou três...

Interrogado sobre a possbilidade de uma edição comercial de sua tradução - a pergunta foi feita antes de ter assinado o contrato para publicá-la em 2012 - e sobre as implicações de seu lançamento, Galindo justifica-a da seguinte forma:

Dizer que ela tem algo a dizer que não foi dito (de todo ou adequadamente) pelas traduções hoje existentes. Melhor? Pior? Não me cabe dizer. Tenho a impressão de que o meu trabalho ainda é muito mais "sujo" que os outros: ele não foi revisado profissionalmente, etc... Mas tenho também a impressão de que ele ocupa um nicho de possibilidades que não é coberto pelos trabalhos de Houaiss e Pinheiro e que, na minha modesta, obviamente, é mais interessante. ${ }^{24}$

\footnotetext{
${ }^{24}$ A citações feitas até este ponto fazem parte de uma duas entrevistas. GALINDO, Caetano Waldrigues. Um Ulisses Bem-Humorado. Entrevista concedida a Dirce Waltrick do Amarante e Sérgio Medeiros. Florianópolis. Disponível em:
} 
Na segunda entrevista concedida ao site Centopéia, é perguntado sobre quais são suas traduções preferidas do Ulysses, em português e em outras línguas. Atentando para os cuidados que se tem de ter ao se fazer crítica de tradução, e anotando suas opiniões sobre as demais traduções em língua portguesa, respondeu a pergunta assim:

hmmm...Nunca analisei assim a fundo as estrangeiras. Apesar de ter montado uma coleção bem razoável de exemplares, que inclui até línguas que eu nem sei pronunciar. Então prefiro não dar grandes juízos de orelhada. A opinião de um leitor de trechos, e mesmo de um "leitor", é muito diferente da do analista, que fez um trabalho mais consciente e tematizado com as traduções. Todo tradutor sabe o que é ouvir críticas levianas e "amostrísticas”. Então não vou fazer aqui a minha.

Das nossas, nunca li o Palma-Ferreira, e em geral me julgo incapaz de dar palpite sobre, por exemplo, a vernacularidade (questão sempre central, por escolha ou negação) de um texto lusitano. Li o Houaiss até onde aguentei e estou lendo a Bernardina com os meninos da graduação. Pouco tenho a acrescentar ao que já se sabe sobre essas duas. E me sinto meio mal, meio em interesse próprio....? Como autor de outra.

Mas continuo recomendando aos leitores de primeira viagem, enquanto não sai a minha (afinal, se nem eu for recomendar a minha....), que comprem a Bernardina/Alfaguara. A tradução ali tem problemas, claro, todas têm. Mas a edição é muito superior ao Houaiss/Civilização. Com algum aparato crítico etc... E, num mundo em que a fortuna crítica na nossa língua é quase inexistente, isso desequilibra bastante a balança.

Acorde com o propósito maior deste dossiê, o de disponibilizar passagens de difícil tradução do Ulysses, lado a lado, para a leitura, crítica e pesquisa, reproduz-se, ao fim, a resposta de Galindo à pergunta sobre quais são, em sua opinião, as passagens ou capítulos mais radicais do Ulysses! Respondeu:

Imagino que a pergunta se refira mais à técnica. E aí a resposta tem de ser "O Gado do Sol." Até por ser o momento em que fica mais em risco o princípio da "necessidade" do radicalismo formal. Em todo o "Ulysses" as coisas acontecem no nível formal graças a alguma necessidade que no fundo remonta a uma convenção de certa forma mimética. O texto fica bêbado quando a personagem bebe, fica com sono quando ela se cansa, fica tenso e impostado quanto o tema é sobre isso etc... Mas a brincadeira, no "Gado",

$<$ http://www.centopeia.net/entrevista/caetano_galindo.php $>$. Acesso em: 15 de novembro de 2010 . 
é muito mais complexa e leva ao limite a compreensibilidade e mesmo a justificabilidade da experiência, ao menos segundo critérios que facilmente dão conta de outros momentos/trechos do livro. Mas, ao mesmo tempo, pode ser essa mesmo a ideia. ${ }^{25}$

Boa leitura e boas pesquisas!

\author{
Gustavo Althoff \& Jolanta Wawrzycka \\ gualthoff@gmail.com/jolanta@radford.edu \\ Universidade Federal de Santa Catarina / Radford University
}

${ }^{25}$ A citações feitas até este ponto fazem parte de uma duas entrevistas. GALINDO, Caetano Waldrigues. O terceiro "Ulisses" do Brasil: Caetano Galindo fala ao site Centopéia sobre James Joyce. Entrevista concedida a Dirce Waltrick do Amarante e Sérgio Medeiros. Florianópolis, 16 de Junho de 2010. Disponível em:

$<$ http://www.centopeia.net/entrevista/galindo.php>. Acesso em: 15 novembro 2010.

Scientia Traductionis, n.8, 2010 